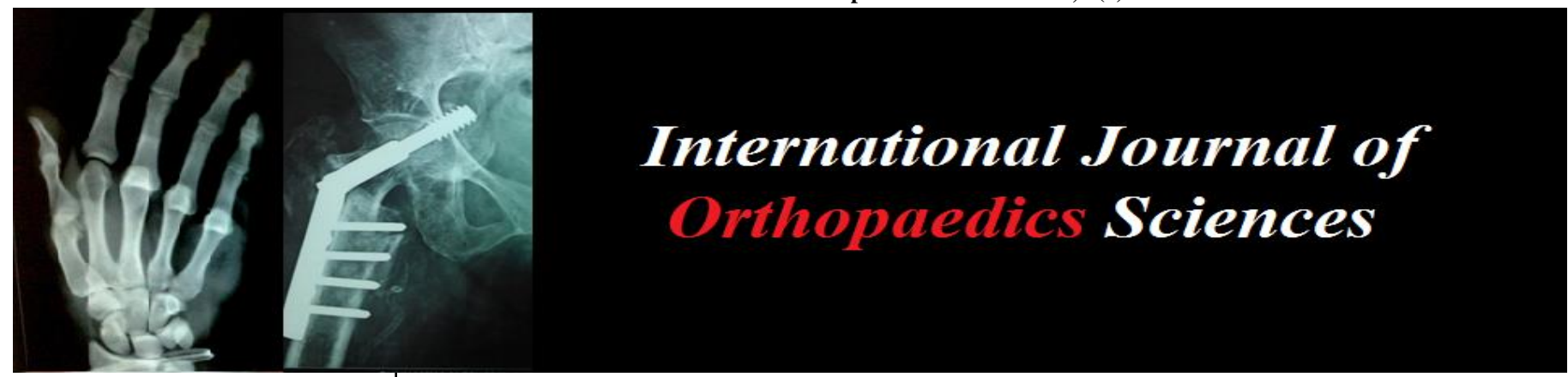

E-ISSN: 2395-1958

P-ISSN: 2706-6630

IJOS 2019; 5(4): 55-59

(C) 2019 IJOS

www.orthopaper.com

Received: 09-08-2019

Accepted: 12-09-2019

Dr. Chowdhury Iqbal Mahmud Assistant Professor, Department of Orthopaedic Surgery, Bangabandhu Sheikh Mujib Medical University BSMMU, Shahbag, Dhaka 1000 ,

Bangladesh

MKI Quayyum Choudhury, Professor, Department of Orthopaedic Surgery BIRDEM Hospital and Ibrahim Medical College, Shahbag, Dhaka 1000, Bangladesh

Dr. Jonaed Hakim

Assistant Professor, Department of Orthopaedic Surgery

BIRDEM Hospital and Ibrahim

Medical College,

Shahbag, Dhaka 1000,

Bangladesh

Corresponding Author: Dr. Chowdhury Iqbal Mahmud Assistant Professor, Department of Orthopaedic Surgery, Bangabandhu Sheikh Mujib Medical University BSMMU, Shahbag, Dhaka 1000 ,

Bangladesh

\section{Evaluation of outcome of primary cemented hemiarthroplasty for intertrochanteric femur fracture in the elderly}

\author{
Dr. Chowdhury Iqbal Mahmud, MKI Quayyum Choudhury and Dr. \\ Jonaed Hakim
}

DOI: https://doi.org/10.22271/ortho.2019.v5.i4b.1649

\section{Abstract}

Introduction: Appropriate treatment method for osteoporotic trochanteric fracture in elderly people is rather controversial because of the poor quality of bone mass, difficult anatomical reduction and accompanying systemic disorders. Internal fixation in these cases usually involves prolonged bed rest, limited ambulation and implant failure secondary to osteoporosis. This might result in higher chances of complications like pulmonary embolism, deep vein thrombosis, pneumonia, and decubitus ulcer. The purpose of this study is to analyse the role of primary cemented hemiarthroplasty in cases of osteoporotic intertrochanteric femur fractures in elderly patients with co-morbities.

Materials and Methods: In this study, 120 cases of primary cemented hemiarthroplasty performed for osteoporotic intertrochanteric fractures were analysed retrospectively. There were 85 female and 35 male. Mean age of the patients were 65.2 years (range, 60-85 years). Harris hip score (HHS) was used to assess the outcome.

Result: The mean Harris hip score at the two-year follow-up was $83.10 \pm 10.90$. A total of 25 patients were graded as excellent, 60 patients as good, 30 as fair and 5 as poor. It was observed that, patients with stable variety of intertrochanteric fractures had better outcome than the unstable variety in our study.

Conclusion: Hemiarthroplasty for osteoporotic intertrochanteric fractures in the elderly patient results in early ambulation and good functional results, although further prospective randomised trials are required before reaching to conclusion.

Keywords: Hemiarthroplasty, osteoporotic fractures, intertrochanteric fractures, elderly patient

\section{Introduction}

Trochanteric femur fracture is one of the most important health problems amongst the elderly population. There were an estimated 1.66 million hip fractures worldwide in $1990^{[1]}$. This worldwide annual number is rising rapidly ${ }^{[2,3]}$ with an expected incidence of 6.26 million by the year $2050^{[1,4]}$. An increase in these fractures is on the rise due to the increased life expectancy of the people and osteoporosis ${ }^{[1,2,3,4]}$.

Appropriate treatment method for trochanteric fracture, particularly in elderly people, is rather controversial because of the poor quality of bone mass, accompanying systemic disorders and discordancy of these patients ${ }^{[5]}$. Rigid internal fixation and early mobilisation are the vital points of the treatment ${ }^{[6]}$. Trochanteric sliding plate fixation (DHS), intramedullary nailing devices (PFN), methyl methacrylate or absorbable ceramic application and proximal femoral osteotomies are the recently used treatment modalities. But these options are not always suitable for osteoporotic intertrochanteric fracture in elderly, because of the inadequate stabilisation, loosening of implants, shortening of the leg and abductor weakness after treatment ${ }^{[7,8]}$.

Trochanteric fractures in elderly patients are associated with high rates of morbidity and mortality ${ }^{[9,10]}$. Comminution, osteoporosis, and instability often preclude the early resumption of full weight bearing in spite of use of internal fixation ${ }^{[10]}$. Reported overall failure rate with internal fixation in intertrochanteric fractures has been reported to be $3-16.5 \%$ [11, 12]. In addition, fracture instability, comminution and osteoporosis in elderly worsen the prognosis [12, ${ }^{13]}$. Moreover, there is a high rate of general complications associated with internal fixation due 
to prolonged recovery time taken after surgery ${ }^{14}$. Excessive collapse of the fracture site and varus displacement is a common problem of dynamic hip screw (DHS) and femoral nails especially in elderly women who often suffer from osteoporosis and poor bone quality ${ }^{[15]}$.

Another treatment option for trochanteric fracture is endoprosthesis application aiming early mobilization with weight bearing, although it isn't the ideal treatment option for stable trochanteric fractures. Various authors have reported successful outcomes after the use of hemiarthroplasty and total hip arthroplasty in these patients $[16,17]$. After hip arthroplasty, patients can bear weight immediately, they can be encouraged to walk early and exercise the involved limb, thus reducing the period of bed rest and rate of complications $[18,19]$.

While relative consensus exists about the treatment of femoral neck fractures for elderly patients, the optimal treatment for intertrochanteric fractures is still under debate ${ }^{[21,22]}$. The purpose of this study is to analyse the role of primary cemented hemiarthroplasty in cases of osteoporotic intertrochanteric femur fractures in elderly patients with comorbidities.

\section{Materials and Methods}

This retrospective study was carried out to review the outcome of 120 cases of trochanteric fractures treated with cemented hemiarthroplasty after at least 2 years follow-up. These surgeries were performed between 2012 to 2017 in the
BIRDEM hospital. Among the 120 patients, there were 85 female and 35 male. Mean age of the patients were 65.2 years (range, 60-85 years). Of the 120 procedures, 70 were on the right and 50 on the left (Table-1).

The fractures were classified according to Evans classification. Evans type I and II (stable) (Figure-1), and III or IV (unstable) (Figure-2) fractures were included in this study. There were 40 patients with stable variety and 80 patients with unstable variety. Patients with associated fractures that might significantly affect the final functional outcome, patients that were non-ambulatory before injury and patients with psychiatric disorders were excluded from the study. All patients were community ambulatories, with or without walking aids, prior to trauma. All the patients were diabetic and had other co-morbidities.

Table 1: Demographic pattern of patients

\begin{tabular}{|c|c|c|c|c|c|c|}
\hline $\begin{array}{c}\text { Number of } \\
\text { patients }\end{array}$ & \multicolumn{2}{|c|}{$\begin{array}{c}\text { Side } \\
\text { involved }\end{array}$} & \multicolumn{2}{|c|}{ Age in years } & \multicolumn{2}{|c|}{ Sex } \\
\hline \multirow{2}{*}{120} & Right & Left & Range & Mean & Male & Female \\
\cline { 2 - 7 } & 70 & 50 & $60-85$ & 65.2 & 35 & 85 \\
\hline
\end{tabular}

Cemented hemiarthroplasty was done by using a standard posterior approach in lateral decubitus position by the same surgical team under spinal anesthesia. A standard stem and a bipolar head were used. Prosthesis stems were cemented using the modern cementing technique.

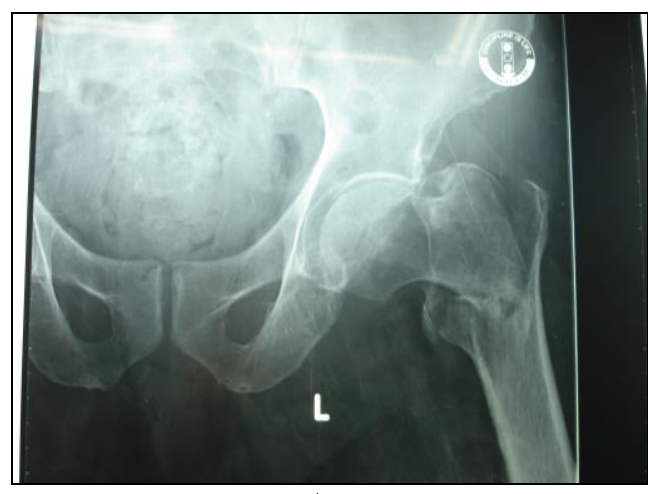

A.

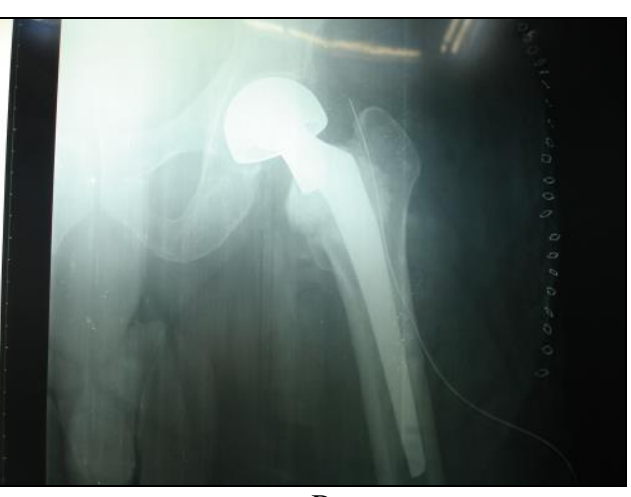

B.

Fig 1: A) Preoperative X-ray of stable intertrochanteric fracture, B) postoperative X-ray after Hemiarthroplasty.

All patients underwent a routine postoperative physiotherapy protocol that included early gait training in form of walking with the help of a walker starting second day post surgery. The rehabilitation then progressed as tolerated by the patients. Patients were examined postoperatively at 6 weeks, 3 months, 6 months, 1 year, and thereafter annually. At each follow-up visit, a clinico-radiological examination was done and the patient was evaluated using the Harris hip score (HHS) and were graded as <70 poor, 70-79 fair, 80-89 good and 90-100 excellent. Anteroposterior and lateral radiographs of the hip were analysed at each follow-up to note evidence of loosening.

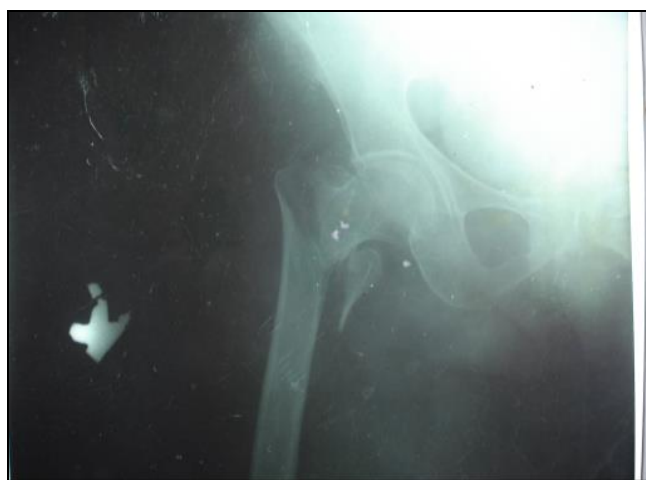

A.

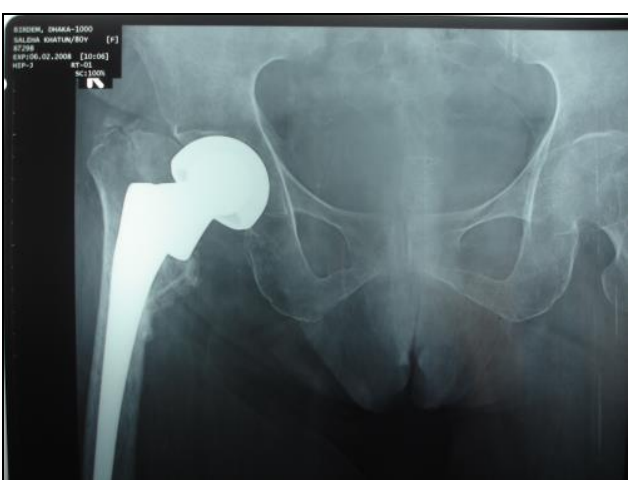

B

Fig 2: A) Preoperative X-ray of unstable intertrochanteric fracture, B) postoperative X-ray after Hemiarthroplasty. 


\section{Results}

All patients were operated within 15 days (mean delay of 5.61 \pm 3.73 days, range 2 days to 14 days) with delay due to patients presenting late and time taken for patients to be fit for anaesthesia. The mean operative time was 80 minutes (range, 60-110 minutes). Average intraoperative blood loss was 295 $\mathrm{ml}$ (range, 150-500) and the average postoperative drainage was $160 \mathrm{ml}$ (range, 40-290). 33 patients needed single unit blood transfusion each postoperatively; rest of the patients did not require any blood transfusion. The patients started full weight bearing at an average 5.5 days after surgery (range, 39 days).One patient refused to walk after surgery and had a poor result (HHS 69). The average stay in the hospital was 10.96 days (range, 5-21 days). One of the patients developed bed sore postoperatively, and required a week more of hospital stay, till the healing of the sore. This patient was operated on 5th day post injury and did not have a pre operative bed sore.

Follow-up period ranged from 2 years to 3.5 years with a mean duration of 2.3 years. Out of the 120 cases, two patients, who were known cases of ischaemic heart disease, died postoperatively following myocardial infarction.

The mean Harris hip score at the two-year follow-up was $83.10 \pm 10.90$. A total of 25 patients were graded as excellent, 60 patients as good, 30 as fair and 5 as poor (Table-2). It was observed that, patients with stable variety (Evans I and II) of intertrochanteric fractures had better outcome than the unstable variety in our study.

At last follow-up (after 2 years), 95 patients were walking without any aid, 15 patients had a limp and used a stick for walking, 6 patients used a walker, and 4 was wheelchair bound. 15 patients had shortening of the operated limb with an average shortening of $1.1 \mathrm{~cm}$ (range, $5-15 \mathrm{~mm}$ ) which was well compensated by giving a shoe raise. A total of 22 patients had an abductor lurch at 3-month follow-up; however, only 10 patients had abductor muscle weakness with a positive Trendelenburg test at final follow-up. Most of these patients however could walk well with the use of a stick.

Table 2: Overall outcome according to Harris Hip Score (HSS)

\begin{tabular}{|c|c|}
\hline Results & No. of Cases (Mean HSS-83.10 \pm 10.90) \\
\hline Excellent & $25(20.83 \%)$ \\
\hline Good & $60(50.00 \%)$ \\
\hline Fair & $30(25.00 \%)$ \\
\hline Poor & $05(4.16 \%)$ \\
\hline
\end{tabular}

Among the patients with poor results, three patients had a superficial wound infection which settled down with a course of intravenous antibiotics for 2 weeks. However, the patient continued to have diffuse pain along the incision site and walked with a limp. Other two patients of poor results also had pain and limp, but we could not find any obvious reason for the pain. There was a case of loosening of prosthesis, which was treated later with cemented bipolar prosthesis. There were no incidence of dislocation, periprosthetic fractures, or late infections.

\section{Discussion}

The incidence of all hip fractures is expected to double over the next 50 years as the population ages ${ }^{[23]}$. All our patients were elderly (mean, 65.2 years) with diabetes and other comorbidities. Most of them had severe osteoporosis. The Intertrochanteric fractures make up $45 \%$ of all hip fractures [24[. Many of these fractures are stable two-part fractures that can be treated satisfactorily with a sliding hip screw (DHS).
But $35-40 \%$ is unstable three and four part fractures that are associated with high rates of morbidity and mortality ${ }^{[24]}$.

In this study, there were 80 patients with unstable and 40 patients with stable intertrochanteric femur fractures. However, all fractures were treated by cemented hemiarthroplasty (Figure 1\&2). We treated many trochanteric fractures with internal fixation (DHS) in our institution. However, our experience showed better outcome in hemiarthroplasty than internal fixation in case of elderly osteoporotic patients. The reported overall failure rate with internal fixation in intertrochanteric fractures is $3-16.5 \%$ [25, 26]. Our study was made with the purpose of presenting the role of primary hemiarthroplasty in cases of osteoporotic intertrochanteric fractures of femur in elderly patients with diabetes.

Since 1971 hemiarthroplasty has been used for unstable intertrochanteric fractures, ${ }^{[27]}$ however less frequently as compared to femoral neck fractures ${ }^{[28]}$. Tronzo claimed to be the first to use long, straight-stemmed prosthesis for the primary treatment of intertrochanteric fractures ${ }^{[29]}$. Stern and Goldstein used the Leinbach prosthesis for the primary treatment of 22 intertrochanteric fractures and found early ambulation and early return to the prefracture status as a definite advantage ${ }^{[30]}$. Liang et al. ${ }^{[31]}$ in their study of unstable intertrochanteric fractures concluded hemiarthroplasty is an effective method to treat the unstable intertrochanteric fractures in elderly. It can decrease the complications, reduce the mortality, improve the patient's living quality, and reduce the burden of the patient's family. Grimsrud et al. ${ }^{[32]}$ studied 39 consecutive patients of unstable intertrochanteric fractures treated with a cemented bipolar hip arthroplasty and observed good results. The technique allows safe and early weight bearing on the injured hip and had a relatively low rate of complications. In our series too, there was only one case of pressure sores and three cases of superficial wound infection. Since most of the patients were out of bed on the second day postoperatively, and the Recumbency time was minimal, there were no chest and urinary tract infection in our series.

Rodop et al. ${ }^{[33]}$ in a study of primary bipolar hemi-prosthesis for unstable intertrochanteric fractures in 37 elderly patients obtained 17 excellent $(45 \%)$ and $14 \operatorname{good}(37 \%)$ results after 12 months according to the Harris hip-scoring system. A total of 85 out of 120 patients in our study had a good to excellent result $(71 \%)$. Thus the results of this modality of treatment are definitely promising especially in view of the variable results of Osteosynthesis in this group.

The opponents of the technique stated increase blood loss, mechanical complications like dislocation, and infection as possible complications as compared to conventional internal fixation. In a comparative study of cone hemiarthroplasty versus internal fixation, Kayali et al. found that the clinical results of both groups were similar ${ }^{[34,36]}$. Hemiarthroplasty patients were allowed full weight bearing significantly earlier than the internal fixation patients. Broos et al. concluded that the operative time, blood loss, and mortality rates were comparable between the two groups, with a slightly higher percentage $(73 \%$ versus $63 \%$ ) of those receiving a prosthesis considered to be pain free ${ }^{[35]}$. Stappaerts et al. found no difference between two groups except a higher transfusion need in the replacement group ${ }^{[36]}$. In our series the average blood loss was $295 \mathrm{ml}$ with only 33 patients requiring postoperative blood transfusion and there was no incidence of dislocation, peri-prosthetic fractures and infection.

Conflicting reports about postoperative mortality in cases 
with primary hemiarthroplasty are cited in the literature. Kesmezacare et al. ${ }^{\text {[37] }}$ reported postoperative mortality in $34.2 \%$ after a mean of 13 months and in $48.8 \%$ after a mean of 6 months in patients treated with internal fixation and endoprosthesis respectively. Other studies have shown no differences in postoperative mortality in two groups ${ }^{[34,36]}$. In present series only 2 patients out of the 120 died postoperatively due to unrelated causes (both secondary to myocardial infarction).

The purpose of the treatment of hip fractures seen in elder population is to prevent the probable complications by providing early mobilization and to help the patients in returning to their daily activities. In spite endoprosthesis surgery is an accepted method in the treatment of femoral neck fractures, there is still controversy for the treatment of trochanteric fractures, particularly in the stable variety. The aim of the internal fixation is to preserve the hip joint and to prevent complications related to prosthesis surgery. Although it isn't a common treatment option, the advantage of the endoprosthesis surgery in the treatment of certain intertrochanteric femur fractures is to provide early mobilization and to prevent the systemic complications due to immobilisation.

In our study, hemiarthroplasty was associated with better functional outcomes. Patients were able to perform their normal activities within a month. All patients demonstrated good functional achievement in spite of their advanced age. We think that activity of the patient before surgery should be taken into consideration when making a decision for surgery. All our patients were community ambulatories before injury and are expected to lead an active life after treatment. That is why, cemented hemiarthroplasty is an good option for intertrochanteric fracture in elderly patients.

\section{Conclusion}

It is certain that the principal objective in intertrochanteric femur fracture is to prevent the possible complications by early mobilization and to help the patient returning to their daily life. These fractures must be treated with considering the age of the patient, mental status, bone quality, and type of the fracture. Primary cemented hemiarthroplasty does provide a stable, pain-free, and mobile joint with acceptable complication rate as seen in our study; however a larger prospective randomised study comparing the use of intramedullary devices against primary hemiarthroplasty for intertrochanteric osteoporotic femur fractures will be needed. We recommend hemiarthroplasty for only carefully selected active elderly diabetic patients with osteoporotic bone.

\section{References}

1. Kannus P, Parkkari J, Sievסnen H, Heinonen A, Vuori I, Jorvinen M. Epidemiology of hip fractures. Bone. 1996; 18:57S-63S.

2. Koval KJ, Zuckerman JD. Hip fractures are an increasingly important public health problem. Clin Orthop Relat Res 1998; 348:2.

3. Rockwood PR, Horne JG, Cryer C. Hip fractures: A future epidemic? J Orthop Trauma. 1990; 4:388-93.

4. Frandsen PA, Kruse T. Hip fractures in the county of Funen, Denmark: Implications of demographic aging and changes in incidence rates. Acta Orthop Scand. 1983; 54:681-6.

5. Sarmiento A, Williams EM. The unstable intertrochanteric fracture: treatment with a valgus osteotomy and I-beam nail plate. A preliminary report of one hundred cases. J Bone Joint Surg [Am]. 1970; 52:1309-18.

6. Miller K, Atzenhofer K, Gerber G, Reichel M. Risk prediction in operatively treated fractures of the hip. Clin Orthop Relat Res. 1993; 293:148-52.

7. DeLee JC. Fractures and dislocations of the hip. In: Rockwood CA Jr, Green DP, Bucholz RW, Heckman JD, editors. Rockwood and Green's fractures in adults. Vol. 2, 4th ed. Philadelphia: Lippincott-Raven, 1996, 1659825.

8. Eastwood EA, Magaziner J, Wang J, Silberzweig SB, Hannan EL, Strauss E. Patients with hip fracture: subgroups and their outcomes. J Am Geriatr Soc. 2002; 50:1240-9.

9. White BL, Fisher WD, Laurin CA. Rate of mortality for elderly patients after fracture of the hip in the 1980's. J Bone Joint Surg. 1987; 69-A: 1335-1340.

10. Said GS, Farouk O, El-Sayed A, and Said HG. Salvage of failed dynamic hip screw fixation of intertrochanteric fractures. Injury. 2006; 37:194-202.

11. Haentjens P, Casteleyn PP, Opedecam P. Hip arthroplasty for failed internal fixation of intertrochanteric and subtrochanteric fractures in the elderly patient. Arch Orthop Trauma Surg. 1994; 113(4):222-227

12. Davis TR, Sher JL, Horsman A, Simpson M, Porter BB, Checketts RG. Intertrochanteric femoral fractures. Mechanical failure after internal fixation. J Bone Joint Surg Br. 1990; 72:26-3.

13. Kim WY, Han CH, Park JI, Kim JY. Failure of intertrochanteric fracture fixation with a dynamic hip screw in relation to pre-operative fracture stability and osteoporosis. Int. Orthop. 2001; 25(6):360-362.

14. Baumgaertner MR, Curtin SL, Lindskog DM. Intramedullary versus extramedullary fixation for the treatment of intertrochanteric hip fractures. Clin Orthop. 1998; 348:87-94.

15. Jones HW, Johnston P, Parker M. Are short femoral nails superior to the sliding hip screw? A meta-analysis of 24 studies involving 3,279 fractures. Int. Orthop. 2006; 30:69-78.

16. Faldini C, Grandi G, Romagnoli M, Pagkrati S, Digennaro V, Faldini O et al. Surgical treatment of unstable intertrochanteric fractures by bipolar hip replacement or total hip replcement in elderly osteoporotic patients. J Orthop Traumatol. 2006; 7(3):117-121.

17. Tronzo RG. The use of an endoprosthesis for severely comminuted trochanteric fractures. Orthop Clin North Am. 1974; 5(4):679-681.

18. Haentjens P, Casteleyn PP, De Boeck H, Handleberg F, Opedcam P. Treatment of unstable intertrochanteric and subtrochanteric fractures in elderly patients. Primary bipolar arthroplasty compared with internal fixation. J Bone Joint Surg Am. 1989; 71:1214-122.

19. Haentjens P, Casteleyn PP, Opdecam P. Primary bipolar arthroplasty or total hip arthroplasty for the treatment of unstable intertrochanteric and subtrochanteric fractures in elderly patients. Acta Orthop Belg. 1989; 60(1):124-128.

20. Blomfeldt R, Tornkvist H, Ponzer S, Soderqvist A, and Tidermark J. Comparison of internal Wxation with total hip replacement for displaced femoral neck fractures. Randomized, controlled trial performed at four years. J Bone Joint Surg Am. 2005; 87:1680-1688.

21. Geiger F, Schreiner K, Schneider S, Pauschert R, 
Thomsen M. Proximal fracture of the femur in elderly patients: the influence of surgical care and patient characteristics on post-operative mortality. Orthopade. 2006; 35:651-658.

22. Zuckerman JD. Hip fractures. N Engl J Med. 1996; 334:1519-1525.

23. Grimsrud C, Monzon RJ, Richman J, Ries MD. Cemented hip arthroplasty with a novel circlage technique for unstable intertrochanteric hip fractures. J Arthroplasty. 2005; 20:337-343.

24. Haentjens P, Casteleyn PP, Opedecam P. Hip arthroplasty for failed internal fixation of intertrochanteric and sub trochanteric fractures in the elderly patient. Arch Orthop Trauma Surg. 1994; 113(4):222-227.

25. Davis TR, Sher JL, Horsman A, Simpson M, Porter BB, Checketts RG. Intertrochanteric femoral fractures. Mechanical failure after internal fixation. J Bone Joint Surg Br. 1990; 72:26-31.

26. Stern MB, Angerman A. Comminuted intertrochanteric fractures treated with a Leinbach prosthesis. Clin Orthop Relat Res. 1987; 218:75-80.

27. Parker MJ, Handoll HH. Replacement arthroplasty versus internal fixation for extracapsular hip fractures. Cochrane Database Syst Rev. 2006; 2:CD000086.

28. Tronzo RG. The use of an endoprosthesis for severely comminuted trochanteric fractures. Orthop Clin North Am. 1974; 5:679-81.

29. Stern MB, Goldstein TB. The use of the Leinbach prosthesis in intertrochanteric fractures of the hip. Clin Orthop Relat Res. 1977; 128:325-31.

30. Liang YT, Tang PF, Guo YZ, Tao S, Zhang Q, Liang XD. Clinical research of hemiprosthesis arthroplasty for the treatment of unstable intertrochanteric fractures in elderly patients. Zhonghua Yi Xue Za Zhi. 2005; 85:3260-2.

31. Grimsrud C, Monzon RJ, Richman J, Ries MD. Cemented hip arthroplasty with a novel cerclage cable technique for unstable intertrochanteric hip fractures. J Arthroplast. 2005; 20:337-43.

32. Rodop O, Kiral A, Kaplan H, Akmaz I. Primary bipolar hemiprosthesis for unstable intertrochanteric fractures. Int. Orthop. 2002; 26:233-7.

33. Haentjens P, Casteleyn PP, De Boeck H, Handelberg F, Opdecam P. Treatment of unstable intertrochanteric and subtrochanteric fractures in elderly patients. Primary bipolar arthroplasty compared with internal fixation. J Bone Joint Surg Am. 1989; 71:1214-25.

34. Broos PL, Rommens PM, Deleyn PR, Geens VR, Stappaerts KH. Pertrochanteric fractures in the elderly: Are there indications for primary prosthetic replacement? J Orthop Trauma. 1991; 5:446-51.

35. Kayali C, Agus H, Ozluk S, Sanli C. Treatment for unstable intertrochanteric fractures in elderly patients: Internal fixation versus cone hemiarthroplasty. J Orthop Surg (Hong Kong). 2006; 14:240-4.

36. Stappaerts KH, Deldycke J, Broos PL, Staes FF, Rommens PM, Claes P. Treatment of unstable per trochanteric fractures in elderly patients with a compression hip screw or with the Vandeputte (VDP) endoprosthesis: A prospective randomized study. J Orthop Trauma. 1995; 9:292-7. 